\title{
3D AIR POLLUTION COMPUTATIONAL FLUID MODELLING DATA ANALYSIS USING TERRESTRIAL LASER SCANNING (TLS) AND UNMANNED AERIAL VEHICLE (UAV) APPROACH
}

\author{
N. Ridzuan ${ }^{1, *}$, U. Ujang ${ }^{1,}$ S. Azri ${ }^{1,}$ and T. L. Choon ${ }^{2}$ \\ ${ }^{1}$ 3D GIS Research Lab, Faculty of Built Environment \& Surveying, Universiti Teknologi Malaysia, Johor, Malaysia - \\ nurfairunnajiha2@graduate.utm.my, \{mduznir, suhaibah\}@utm.my \\ ${ }^{2}$ Geoinformation, Faculty of Built Environment \& Surveying, Universiti Teknologi Malaysia, Johor, Malaysia - tlchoon@ utm.my
}

KEY WORDS: Terrestrial Laser Scanning, Unmanned Aerial Vehicle, CFD, 3D Building Model, Air Pollution.

\begin{abstract}
:
Air pollution is a global event that can harm the environment and people. It is recommended that effective management be implemented to allow for the sustainable development of a specific area. The 3D building model is employed in the study to support air pollution modelling for this purpose. A proper mode of data acquisition is required to produce the building model. Many data acquisition (Terrestrial Laser Scanning and Unmanned Aerial Vehicle) approaches can be utilized, but the most appropriate one for the use in outdoor air pollution is needed. This is because it can assist in providing precise data for the modelling of a 3D building while maintaining the shape and geometry of the real-world structure. The accurate data can support modelling of surrounding air pollution concerning wind data and surrounding conditions, where different generated structures can influence the flow of the pollutants. The suitable model can be determined by using suitability analysis and with the implementation of Computational Fluid Dynamics (CFD) simulation. However, from these, no specific technique is chosen because the generated models presented incomplete model. Hence, it is suggested to combine both techniques to acquire building data as the missing surfaces from each technique can be completed by another technique. Thus, this study provides a good reference for responsible agencies or researchers in selecting the best technique for modelling the building model in air pollution-related studies.
\end{abstract}

\section{INTRODUCTION}

Air pollution is one of the environmental issues that can affect human health (Manisalidis et al., 2020; Nugumanova et al., 2017). Cardiovascular illness (Lelieveld et al., 2019; Rajagopalan et al., 2018), kidney disease (Afsar et al., 2019), and cardiometabolic disease (Brook et al., 2018) are examples of diseases caused by this type of pollution. Good management and monitoring of outdoor air pollution are needed to ensure that the event is not well spread. The dispersion of air pollutants is associated with wind flow. The presence of building structures influences the velocity and direction of the wind flow. (Yang et al., 2020). The current building model in outdoor air pollution modelling can therefore be used to forecast and visualise pollutant flow in response to a certain wind velocity in the appropriate research area, including the impact of the structure's shape and size on the modelling process.

This air pollutant dispersion are discussed in previous researches (Fang et al., 2009; Ridzuan et al., 2020; Ujang et al., 2015). Street canyon modelling in a 3-dimensional (3D) environment can provide better results and outputs. This is because air pollution dispersion does not move in horizontal plane only. Due to its random movement characteristic, there are possibilities that it will move in a vertical plane. Therefore, detailed 3D modelling is important to produce reliable air pollution modelling output (Ridzuan \& Ujang, 2021).

So, well representation of the building model from the realworld building is needed because the missing structures can impact the dispersion modelling. There are numerous methods and techniques for monitoring. However, these techniques rely on which applications it is utilized and analysed. For example like it is applied in 3D city modelling (Uznir et al., 2013), rainfall-runoff modelling (Yusoff et al., 2010; Liu et al., 2010), smart city (Azri et al., 2019; Jovanović et al., 2020; Vinod Kumar, 2020) or geomarketing application (Azri et al., 2020). However, building data and models required to model air pollution in an urban region or any other study area are with the presence of buildings. Hence, the first step in modelling the building is by performing building data acquisition. Two techniques can be used to capture the data: TLS and drone/Unmanned Aerial Vehicle (UAV). These two methods are selected because they can capture the outdoor detail of the building model while presenting high accuracy of data (Son et al., 2020).

TLS, which stands for Terrestrial Laser Scanning, is one of the methods that can be implemented to obtain the building data. This technology measures spatial data or information using a laser within a certain ground distance from the object (Fabbri et al., 2017; Fernández-Lozano \& Gutiérrez-Alonso, 2016; Hoon $\&$ Hong, 2019). The measurement yields a point cloud (Klapa et al., 2017) of the measured objects, which can be utilised in modelling. Data collection is also done with the use of unmanned aerial vehicles (UAVs). It is a technology equipped with a camera of high-resolution (Jeong et al., 2020) to be used in capturing the object data. Also, UAV has the ability to cruise or hover at a relatively low altitude over a building or study objects, providing additional, comprehensive data on building facades (Xiong et al., 2020).

Henceforth, this study will critically determine the suitable technique for modelling 3D air pollution by referring to these two techniques provided. It is crucial to use the best technique because the accuracy of the data collected will have an impact on future modelling. The model created using both methods is 
used in a CFD simulation to provide an overview of how pollutants flow in relation to the wind profile. All criteria needed in this modelling will be taken into consideration in choosing the best method.

\section{METHODOLOGY}

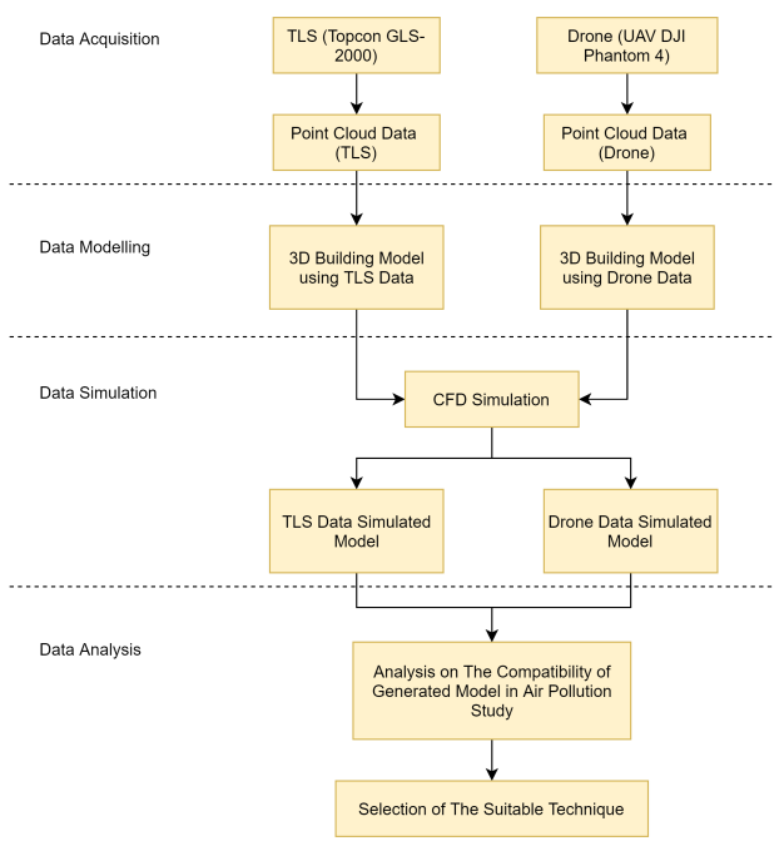

Figure 1. Flowchart of the process in determining the suitable technique to be implemented in air pollution study.

The methods used in this study are depicted in Figure 1. There are four phases: data acquisition, data modelling, data simulation, and analysis. The next section provides a description of these four phases.

\subsection{Data Acquisition}

The data required for this study is building data. This data is needed because in an air pollution study associated with outdoor wind simulation, the existence of a building is one of the factors that can influence the wind flow. As a result, having the building's information is required. In this study, building data is collected using two different techniques: Terrestrial Laser Scanning (TLS) and Unmanned Aerial Vehicle (UAV). TLS of model Topcon GLS-2000 and UAV of DJI Phantom 4 model are used to capture the building data. This building data is a building (Dewan Serbaguna Taman Kobena) located in Taman Kobena, Johor, with approximately $2000 \mathrm{~m}^{2}$ area size (Figure 2). TLS technique, in which the instrument (TLS) is placed surround the building from a station to the others to get the whole building modelling, produce the building model in the form of point cloud data. This dense coloured point cloud to represent the building is shown in Figure 3. Meanwhile, aerial photos of Taman Kobena's building were captured using the UAV technique. These images exist in a quite high number and of high resolution because of the overlapping setting on the drone system to enable a good representation of the captured building. The images are processed in Pix4D software. Also, by using this software, the point cloud was generated from the input images (Figure 4). Then, a 3D representation of the building was created using the point cloud data.

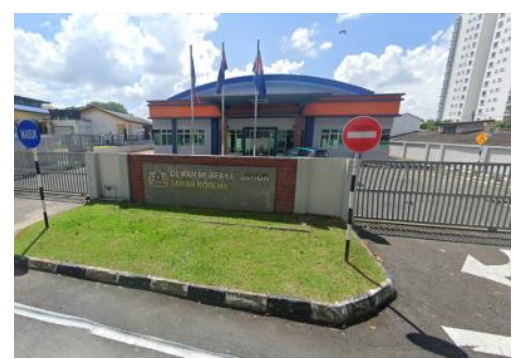

Figure 2. Front view of Dewan Taman Kobena, Johor.

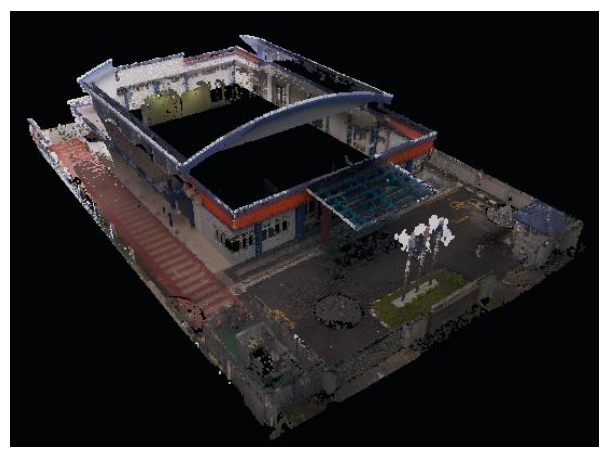

Figure 3. Point cloud from TLS technique.

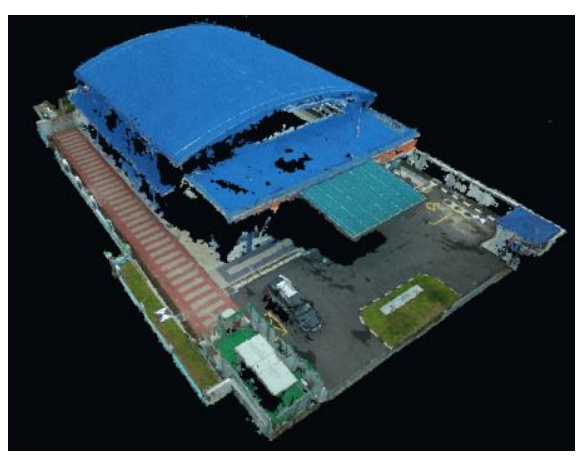

Figure 4. Point cloud from UAV technique.

\subsection{Data Modelling}

SketchUp software is used to process the acquired point cloud data of the building via TLS and UAV techniques. Prior to importing the data into the SketchUp software, no noise reduction was performed. This is because the data collected is sufficient to generate a 3D model of the building in the study area. The processing in this software was carried out to create a 3D model of Dewan Serbaguna Taman Kobena. In the SketchUp software (as mentioned earlier), the "Undet" extension is used to support the modelling processing where; this extension used point cloud data as the input data, and the output data is the $3 \mathrm{D}$ building model which is generated by referring to the existed point cloud's location. The surface colour and texture specification can be done manually during the generation of the model.

\subsection{Data Simulation}

The simulation involved in this study is called Computational Fluid Dynamics simulation which is known as CFD simulation. It supports the simulation of fluid throughout the study area. In this study, the fluid involved is the air or wind. The simulation was performed on both of the models created in the preceded 
phase. The average wind velocity of $2 \mathrm{~m} / \mathrm{s}$ is applied in the simulation that was run in Autodesk CFD software using .step file format. The wind velocity selected is based on the mean velocity of the wind (Ahmad et al., 2018); experienced in Malaysia (study area is located in Johor, Malaysia). Besides, as wind velocity is one of the aspects that can manipulate the air pollutants dispersion, thus, this information is embedded in the simulation process to represent the dispersion surround the building generated.

\subsection{Data Analysis}

Suitability analysis is the type of analysis that is done at this phase. This study used the TLS and UAV-generated 3D building model to determine the best technique for supporting 3D building modelling, which can then be used in an air pollution study. The method of operating the instrument, the capturing process, the complexity of the methodology employed, the type of models developed, and the outcome obtained from the approach are all factors taken into account when conducting the study. The ability to select an acceptable technique that correctly matches the characteristics of a building model while also being convenient supports the decision.

\section{RESULTS}

This study yielded several outcomes, beginning with the data acquisition phase, followed by data modelling and data simulation, and finally, data analysis.

\subsection{D Building Model}

In this study, two 3D building models are generated. The first model is developed by using the point cloud from the TLS approach (Figure 5). As referred to in the figure, the model generated shows no roof presence; nevertheless, the second model (Figure 6) is based on the UAV technique presents the model with the existence of roof surface but with no wall information. As indicated in the figures, the models exhibit different degrees of completeness in terms of the structure of the actual building model.

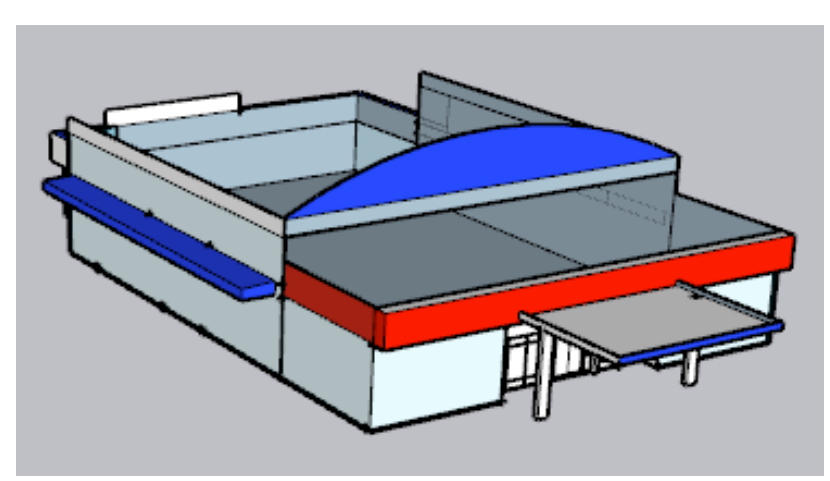

Figure 5. 3D model created from TLS technique.

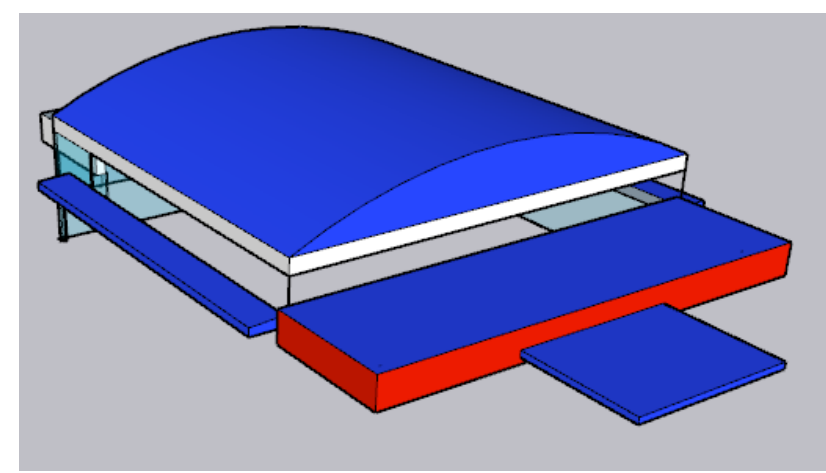

Figure 6. 3D model generated from UAV technique.

\subsection{CFD Simulation}

The generated model by using point cloud from TLS and UAV technique are used in CFD simulation to display the effect of the presence of building structure on the flow of wind surrounding it. Figure 7 below shows the result of simulation by utilizing both models in each simulation. Noted that only a single direction of wind is used, where it is coming from the front of the building with the velocity of $2 \mathrm{~m} / \mathrm{s}$. Also, as there is only a single building used to represent the method, there is no effect of city furniture are included, which is beyond the scope of this study.

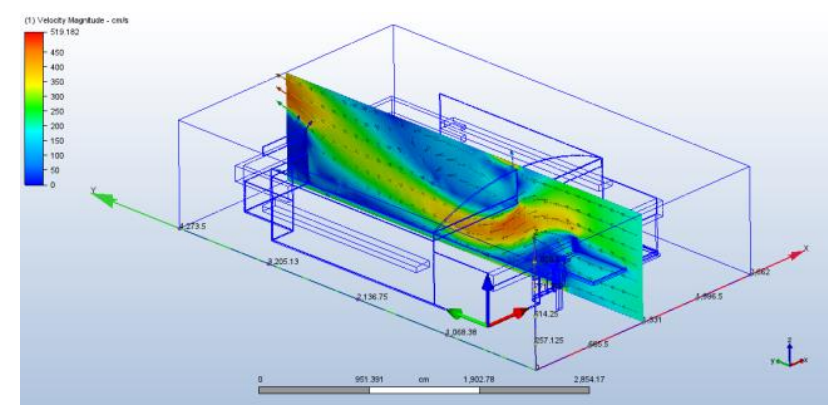

(a)

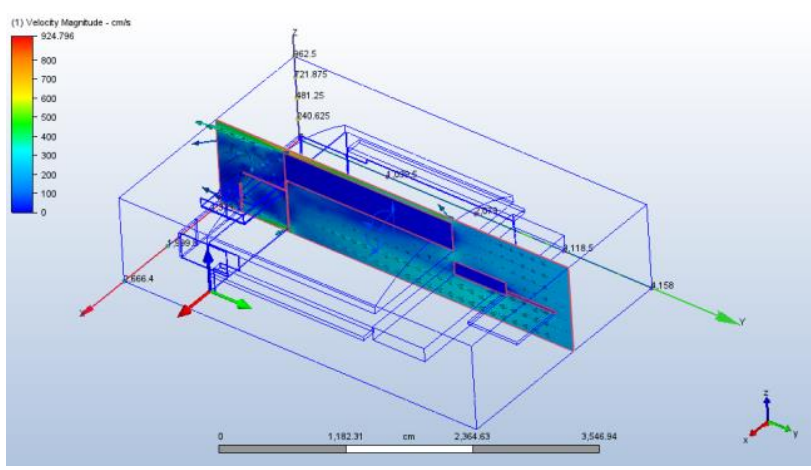

(b)

Figure 7. CFD simulation. (a) Wind flow affected by building model from TLS technique. (b) Generated simulation of wind with influence of model of UAV method. 


\subsection{Suitability Analysis}

This type of analysis considers several factors, including how the instrument is operated, the capturing style, the complexity of selected approaches, types of models generated, and the appearance model derived from data collected using TLS and UAV techniques. The outcome of this analysis is shown in Table 1 below. TLS will capture all data throughout the scanning process in terms of operation, and it is also the same for UAV. Still, the advantage of using UAV is that the area covered can be specified by following the commanded flight plan. Furthermore, the capturing process enables in showing the difference between these two techniques. TLS is a ground-based instrument with high complexity, whereas UAV is a flight-based instrument with a more straightforward implementation. However, there is one commonality between these two techniques, where the type of model used in the simulation are the Computer-Aided Design (CAD). The last one concerns the model's appearance. TLS displays more details on the model than the UAV technique, representing only the roof surface perfectly.

\begin{tabular}{|c|c|c|c|c|}
\hline Criteria & \multicolumn{4}{|c|}{ Technique } \\
\hline & \multicolumn{2}{|c|}{ TLS } & \multicolumn{2}{|c|}{ UAV } \\
\hline Operation & \multicolumn{2}{|c|}{$\begin{array}{l}\text { Capture all data } \\
\text { within scanning } \\
\text { angle }\end{array}$} & \multicolumn{2}{|c|}{$\begin{array}{c}\text { Capture data } \\
\text { following flight plan }\end{array}$} \\
\hline $\begin{array}{c}\text { Capturing } \\
\text { process }\end{array}$ & \multicolumn{2}{|c|}{$\begin{array}{l}\text { Placed instrument } \\
\text { on the ground }\end{array}$} & \multicolumn{2}{|c|}{$\begin{array}{l}\text { Instrument used from } \\
\text { the air }\end{array}$} \\
\hline $\begin{array}{c}\text { Complexity } \\
\text { level }\end{array}$ & \multicolumn{2}{|c|}{ High } & \multicolumn{2}{|c|}{ Low } \\
\hline $\begin{array}{c}\text { Type of model } \\
\text { generated }\end{array}$ & \multicolumn{2}{|c|}{ CAD } & \multicolumn{2}{|c|}{ CAD } \\
\hline Appearance & $\begin{array}{c}\text { Roof } \\
\text { Wall } \\
\text { Door } \\
\text { Window } \\
\end{array}$ & $\begin{array}{l}\text { Absent } \\
\text { Present } \\
\text { Present } \\
\text { Present }\end{array}$ & $\begin{array}{c}\text { Roof } \\
\text { Wall } \\
\text { Door } \\
\text { Window } \\
\end{array}$ & $\begin{array}{l}\text { Present } \\
\text { Absent } \\
\text { Absent } \\
\text { Absent }\end{array}$ \\
\hline
\end{tabular}

Table 1. Criteria shown by TLS and UAV technique.

\section{DISCUSSION}

In this study, two techniques are employed in acquiring building data, which will eventually be used in outdoor air pollution research. Because the presence of buildings affects the flow of pollutants, three-dimensional (3D) building data is included in outdoor air pollution research (Yang et al., 2020). The dispersion of pollutants in a specific study area can thus be better visualized using a building model. As an outcome, a building model is required for the investigation of pollution flow. Simultaneously, the building displayed must be a decent depiction of the real-world building in terms of resemblance and accuracy. Because of the remarkable accuracy of the acquired data of the building, these two approaches, TLS and UAV, were chosen to meet this requirement (Son et al., 2020).

The accuracy of data presented using these two techniques is up to the centimetre level (Abbas et al., 2021; Mulakala, 2019). When data achieve this level of precision, it is referred to as high precision data, which is very useful in air pollution research. To further explain, building data that is too precise, down to the millimetre level, cannot support showing the effect of air pollutants flow. In contrast, data with low precision cannot present the correct action of pollutants flow because the shape and geometry of the building are not accurate enough to represent a real-world building. For the purpose of performing CFD simulation, this precision level applied on both techniques can help produce a building model of real-world scale, which can allow a good representation of fluid flow with respect to the real size of the building model.

Nonetheless, the data acquired through these two methods must be processed further because the gathered data, which is in the form of a point cloud, cannot be utilized because it is not a solid and rigid model. It is only data with a high density of points and no connective line. Although the shape and geometry of the building can be imagined from a user's perspective, as seen in Figures 3 and 4, a complete model with perfectly connected points is essential for studies such as air pollution. Hence, the point cloud data is turned into a 3D model, allowing the shape of the building to be observed.

Because of the different methodologies utilised to construct the 3D building models, such as Figures 5 (TLS method) and 6 (UAV technique), the final models depicted different architectures. The created model from the TLS approach has all of the building structures complete, except for the roof, which is missing because the instrument is on the ground (Wallace et al., 2017). The scanner is implemented in the instrument to capture building data from a specified angle regarding the instrument's height. Although the scanner can gather data at its inclination angle, it cannot reach the high level of the roof because the equipment is on the ground. Ergo, it is unable to acquire data that is beyond its capabilities. Thus, resulting in the absence of the roof structure. Despite its capability to capture more details of the building model, it is relatively complicated to implement due to the executor's need to move the instrument to several different stations to cover the entire study region.

Furthermore, as shown in Figure 6, the UAV technique accurately represents the roof surface compared to the TLS technique. However, it provides little or no information on other structures such as walls, windows, and doors because the technology is implemented during the flight, flying from the sky (Duan et al., 2019; Mu et al., 2020). Accordingly, it captures data that can only be seen through the instrument's camera. This approach has good coverage on surfaces or structures that can be monitored from above, such as a building's roof surface. The usage of the flight plan function also makes capturing data with this instrument easier. This ability makes this technique less complex because the specified flight plan allows the entire movement of the instrument in the study area in a single flight. Also, the instrument does not need to be set up in a different location. Consequently, the roof may be presented well using the UAV technology, but not the other structures on the side of the building, which do not fall within the angle captured by the UAV camera.

Besides, to execute CFD simulation for the purpose of visualising the flow of pollutants or wind, one specific model type needs to be followed: the data used has to be in CAD standard (Piepereit et al., 2019; Votyakov \& Papanicolas, 2017). From the generation process for both 3D building models, this study used CAD standard models. Specifically, the step file format of models is used, where this format exists within the CAD environment (Kirkwood \& Sherwood, 2017). As a result, it can be employed in this study's CFD simulation of wind flow on two building models. As shown in Figure 7, the two 3D building models support the simulation where the flow can be clearly observed from the results. This simulation can still be performed in software since the building models adhere to the model's standard, which is necessary for simulation generation. However, the wind can flow through the building 
because of the incomplete structure, even show the simulation inside the building. Yet, it is inadequate for modelling the flow outside the building.

On the other hand, this study focuses on the exterior structures of the building, such as walls, roofs, windows, and doors, rather than the interior structures because the model used in the air pollution study only required the exterior structure. After all, the air pollution study mentioned here only pertains to outdoor air pollution. Instead, these structures are the primary components of a building model, and without them, the building will appear as an incomplete model, so-called an open model. Because the open area allows pollutants to flow into the building (involve indoor air pollution) without following the scope of outdoor air pollution, this open model cannot be employed in air pollution modelling.

Thus, the main aspect that needs to follow when modelling the flow of fluid surrounds a building is the completeness of structure to replicate the real-world building. Although the simulation can be executed, its accuracy has been called into question. Following that, only certain environmental factors such as temperature or pressure, as well as pollutants data, can be assigned to the simulation in order to accurately present the pollutants flow.

According to the analysis, both techniques' data yields meet the needs of air pollution studies in terms of data accuracy; however, each technique demonstrates that it cannot properly support 3D modelling in terms of building structures. Although each technique has its own advantages and disadvantages, no single technique can be employed alone. Instead, combining and integrating both techniques yield a comprehensive representation of the building model. This is because the TLS technique's lack of roof structures may be filled by the UAV technique's presence of a roof, and the model will be completed because the TLS data provides the wall, window, and door data. These two techniques' point cloud data are used to create a complete real-world representation of buildings that need to be modelled.

\section{CONCLUSION}

This study investigates two distinct methods for creating a 3D building model. The first technique uses the TLS of the Topcon GLS-2000 model, while the second employs the DJI Phantom 4 UAV. An appropriate technique for data collecting for the building model used in the air pollution study is chosen from these two techniques. The generated models from both techniques represent different detailing structures, with the TLS model having an excellent depiction of the wall, window, and door. In contrast, the UAV model has a good portrayal of the roof surface. TLS covers a region that allows the instrument for collecting data from the control point or the ground level. Meanwhile, UAV is for data collection from the overhead view of the research area, resulting in differences in the structure details due to the different abilities of both techniques. Additionally, TLS is more complicated than UAV since it requires multiple ground stations to collect data, whereas UAV need a single flight in the air to do so. However, through the CFD simulation conducted, both models show the representation of wind flow despite the incomplete structures on the models. Although each technique has drawbacks, the air pollution dispersion related study cannot implement only one technique. Thus, it is recommended that two techniques be combined because both procedures' ability to fill in the gaps in each other's missing data. To summarise, two amalgamated techniques, TLS and UAV, are required to model the 3D building in an air pollution study to give a complete 3D building model.

\section{ACKNOWLEDGEMENTS}

This research was partially funded by UTM Research University Grant, Vot Q.J130000.2452.09G84 and Vot Q.J130000.3652.02M78.

\section{REFERENCES}

Abbas, M. A., Zainuddin, K., Darwin, N., Azmi, M. A. A. M., Opaluwa, Y. D., Sulaiman, S. A., \& Hashim, N. M. (2021). Three-dimensional data quality assessment: Unmanned aerial vehicle photogrammetry and mobile laser scanner. Engineering Journal, 25(1), 143-154. https://doi.org/10.4186/ej.2021.25.1.143

Afsar, B., Elsurer Afsar, R., Kanbay, A., Covic, A., Ortiz, A., \& Kanbay, M. (2019). Air pollution and kidney disease: Review of current evidence. In Clinical Kidney Journal (Vol. 12, Issue 1, pp. 19-32). Oxford University Press. https://doi.org/10.1093/ckj/sfy111

Ahmad, A. S., Yusuf, A. M., Majid, S., Rahman, H. A., \& Hassan, M. Y. (2018). Wind Power Harnessing Based on Senai Meteorological Data, Malaysia. International Journal of Computational Intelligence in Control, 4(1), 7-14.

Azri, S., Ujang, U., \& Rahman, A. A. (2019). 3D GeoClustering for Wireless Sensor Network in Smart City. ISPAr, 4212(4/W12), 11-16. https://doi.org/10.5194/ISPRSARCHIVES-XLII-4-W12-11-2019

Azri, Suhaibah, Ujang, U., \& Abdul Rahman, A. (2020). Voronoi classified and clustered data constellation: A new 3D data structure for geomarketing strategies. ISPRS Journal of Photogrammetry and Remote Sensing, 162, 1-16. https://doi.org/10.1016/J.ISPRSJPRS.2020.01.022

Brook, R. D., Newby, D. E., \& Rajagopalan, S. (2018). Air Pollution and Cardiometabolic Disease: An Update and Call for Clinical Trials. In American Journal of Hypertension (Vol. 31, Issue 1, pp. 1-10). Oxford University Press. https://doi.org/10.1093/ajh/hpx109

Fabbri, S., Sauro, F., Santagata, T., Rossi, G., \& De Waele, J. (2017). High-resolution 3-D mapping using terrestrial laser scanning as a tool for geomorphological and speleogenetical studies in caves: An example from the Lessini mountains (North Italy). Geomorphology, 280, 16-29. https://doi.org/10.1016/j.geomorph.2016.12.001

Fang, M., Chan, C. K., \& Yao, X. (2009). Managing air quality in a rapidly developing nation: China. Atmospheric Environment, 43(1), 79-86. https://doi.org/10.1016/J.ATMOSENV.2008.09.064

Fernández-Lozano, J., \& Gutiérrez-Alonso, G. (2016). Improving archaeological prospection using localized UAVs assisted photogrammetry: An example from the Roman Gold District of the Eria River Valley (NW Spain). Journal of Archaeological Science: Reports, 5, 509-520. https://doi.org/10.1016/j.jasrep.2016.01.007 
Hoon, Y. J., \& Hong, S. (2019). Three-dimensional digital documentation of cultural heritage site based on the convergence of terrestrial laser scanning and unmanned aerial vehicle photogrammetry. ISPRS International Journal of GeoInformation, 8(2). https://doi.org/10.3390/ijgi8020053

Jeong, G. Y., Nguyen, T. N., Tran, D. K., \& Hoang, T. B. H. (2020). Applying unmanned aerial vehicle photogrammetry for measuring dimension of structural elements in traditional timber building. Measurement: Journal of the International Measurement Confederation, https://doi.org/10.1016/j.measurement.2019.107386

Jovanović, D., Milovanov, S., Ruskovski, I., Govedarica, M., Sladić, D., Radulović, A., \& Pajić, V. (2020). Building virtual 3D city model for smart cities applications: A case study on campus area of the university of novi sad. ISPRS International Journal of Geo-Information, 9(8). https://doi.org/10.3390/IJGI9080476

Kirkwood, R., \& Sherwood, J. A. (2017). Sustained CAD/CAE integration: integrating with successive versions of step or IGES files. Engineering with Computers 2017 34:1, 34(1), 1-13. https://doi.org/10.1007/S00366-017-0516-Z

Klapa, P., Mitka, B., \& Zygmunt, M. (2017). Application of Integrated Photogrammetric and Terrestrial Laser Scanning Data to Cultural Heritage Surveying. IOP Conference Series: Earth and Environmental Science, 95(3), 32007. https://doi.org/10.1088/1755-1315/95/3/032007

Lelieveld, J., Klingmüller, K., Pozzer, A., Pöschl, U., Fnais, M., Daiber, A., \& Münzel, T. (2019). Cardiovascular disease burden from ambient air pollution in Europe reassessed using novel hazard ratio functions. European Heart Journal, 40(20), 1590-1596. https://doi.org/10.1093/eurheartj/ehz135

Liu, X., Liu, W., \& Hu, J. (2010). Analysis and dynamic simulation of urban rainstorm waterlogging. Sixth International Symposium on Digital Earth: Data Processing and Applications, 7841, 78411M. https://doi.org/10.1117/12.873276

Manisalidis, I., Stavropoulou, E., Stavropoulos, A., \& Bezirtzoglou, E. (2020). Environmental and Health Impacts of Air Pollution: A Review. In Frontiers in Public Health (Vol. 8, p. 14). Frontiers Media S.A. https://doi.org/10.3389/fpubh.2020.00014

Mulakala, J. (2019). Measurement Accuracy of the DJI Phantom 4 RTK \& Photogrammetry. DroneDeploy, Tech. Rep.

Nugumanova, L., Frey, M., Yemelina, N., \& Yugay, S. (2017). Environmental Problems and Policies in Kazakhstan: Air pollution, waste and water. www.ios-regensburg.de

Piepereit, R., Beuster, A., Von Der Gruen, M., Voß, U., Pries, M., \& Wagner, U. (2019). Towards Wind-Simulation of Virtual 3D City Models in A Collaborative VR Environment. 14th 3D GeoInfo Conference. https://doi.org/10.5194/isprs-archivesXLII-4-W15-61-2019

Rajagopalan, S., Al-Kindi, S. G., \& Brook, R. D. (2018). Air Pollution and Cardiovascular Disease: JACC State-of-the-Art Review. In Journal of the American College of Cardiology
(Vol. 72, Issue 17, pp. 2054-2070). Elsevier USA. https://doi.org/10.1016/j.jacc.2018.07.099

Ridzuan, N., \& Ujang, U. (2021). Determination Of Suitable Level of Details (Lod) Of 3d Building Model For Air Pollutants Dispersion Study. Paper presented at the 6th Geoinformation Research Colloquium, Morocco

Ridzuan, N., Ujang, U., Azri, S., \& Choon, T. L. (2020). Visualising urban air quality using AERMOD, CALPUFF and CFD models: A critical review. International Archives of the Photogrammetry, Remote Sensing and Spatial Information Sciences - ISPRS Archives, 44(4/W3), 355-363. https://doi.org/10.5194/isprs-archives-XLIV-4-W3-2020-3552020

Son, S. W., Kim, D. W., Sung, W. G., \& Yu, J. J. (2020). Integrating UAV and TLS Approaches for Environmental Management: A Case Study of a Waste Stockpile Area. Remote Sensing, 12(10), 1615. https://doi.org/10.3390/rs12101615

Ujang, U., Anton, F., Ariffin, A., Mioc, D., \& Azri, S. (2015). An amalgamation of 3D city models in Urban air quality modelling for improving visual impact analysis. WIT Transactions on Ecology and the Environment, 198, 51-61. https://doi.org/10.2495/AIR150051

Uznir, U., Anton, F., Suhaibah, A., Rahman, A. A., \& Mioc, D. (2013). Improving 3D spatial queries search: Newfangled technique of space filling curves in $3 \mathrm{D}$ city modeling. ISPRS Annals of the Photogrammetry, Remote Sensing and Spatial Information Sciences, 2(2W1), 319-327. https://doi.org/10.5194/ISPRSANNALS-II-2-W1-319-2013

Vinod Kumar, T. M. (2020). Smart environment for smart cities. In Advances in 21st Century Human Settlements (pp. 153). Springer. https://doi.org/10.1007/978-981-13-6822-6_1

Votyakov, E. V, \& Papanicolas, C. N. (2017). Consistent multiphysics simulation of a central tower CSP plant as applied to ISTORE. AIP Conference Proceedings, 1850, 210019. https://doi.org/10.1063/1.4984561

Xiong, C., Li, Q., \& Lu, X. (2020). Automated regional seismic damage assessment of buildings using an unmanned aerial vehicle and a convolutional neural network. Automation in Construction, 109, 102994. https://doi.org/10.1016/j.autcon.2019.102994

Yang, J., Shi, B., Shi, Y., Marvin, S., Zheng, Y., \& Xia, G. (2020). Air pollution dispersal in high density urban areas: Research on the triadic relation of wind, air pollution, and urban form. Sustainable Cities and Society, 54. https://doi.org/10.1016/j.scs.2019.101941

Yusoff, I. M., Ujang, U., Rahman, A. A., \& Katimon, A. (2010). Georeference, rainfall-runoff modeling and 3D dynamic simulation: Physical influence, integration and approaches. Paper presented at the ACM: 1st International Conference and Exhibition on Computing for Geospatial Research \& Application, Washington, DC 